\title{
Prenatal Diagnosis of Severe Fetal Hydronephrosis Due to Pyeloureteral Junction Syndrome with False Neonatal Resolution
}

\author{
Gerarda Gaeta ${ }^{1,+}{ }^{,}$Mirko Pozzoni ${ }^{1,+}+\mathcal{C}$, Audrey Serafini ${ }^{1}$, Arianna Lesma ${ }^{2}$, Pier Luigi Paesano ${ }^{3}$, \\ Massimo Candiani ${ }^{1}$ and Paolo Ivo Cavoretto ${ }^{1, *(\mathbb{D})}$ \\ 1 Department of Obstetrics and Gynecology, San Raffaele Scientific Institute, 20132 Milan, Italy; \\ gaeta.gerarda@hsr.it (G.G.); pozzoni.mirko@hsr.it (M.P.); audrey.serafini@ospedaleniguarda.it (A.S.); \\ candiani.massimo@hsr.it (M.C.) \\ 2 Department of Urology, San Raffaele Scientific Institute, 20132 Milan, Italy; lesma.arianna@hsr.it \\ 3 Department of Radiology, San Raffaele Scientific Institute, 20132 Milan, Italy; paesano.pierluigi@hsr.it \\ * Correspondence: cavoretto.paolo@hsr.it \\ + Authors contributed equally to this paper.
}

check for

updates

Citation: Gaeta, G.; Pozzoni, M.; Serafini, A.; Lesma, A.; Paesano, P.L.; Candiani, M.; Cavoretto, P.I. Prenatal Diagnosis of Severe Fetal

Hydronephrosis Due to Pyeloureteral Junction Syndrome with False Neonatal Resolution. Reprod. Med. 2021, 2, 163-170. https://doi.org/ $10.3390 /$ reprodmed 2040017

Academic Editor: Berthold Huppertz

Received: 9 October 2021

Accepted: 2 November 2021

Published: 15 November 2021

Publisher's Note: MDPI stays neutral with regard to jurisdictional claims in published maps and institutional affiliations.

Copyright: (c) 2021 by the authors. Licensee MDPI, Basel, Switzerland. This article is an open access article distributed under the terms and conditions of the Creative Commons Attribution (CC BY) license (https:/ / creativecommons.org/licenses/by/ $4.0 /)$.

\begin{abstract}
A case of severe fetal hydronephrosis due to isolated bilateral stenosis of the pyeloureteral junction was diagnosed at our centre. Surprisingly, a negative renal ultrasound scan was performed on the 3rd postnatal day. An ultrasound follow-up showed severe bilateral pyelectasis a few weeks later. The infant underwent bilateral pyeloplasty at six months of age with an excellent outcome. Such a neonatal picture may be due to the reduction of urinary output secondary to excessive postnatal weight loss and dehydration. In this case, prenatal ultrasound result was more reliable than postnatal ultrasound, emphasizing the importance of postnatal urologic follow-up after prenatal indication.
\end{abstract}

Keywords: ultrasound; prenatal diagnosis; hydronephrosis; pyelo-ureteral junction stenosis; dehydration

\section{Introduction}

Fetal hydronephrosis is a common, easily diagnosed finding on prenatal ultrasound examination occurring in 1 to $2 \%$ of pregnancies (twice as often in males than in females) [1]. It is bilateral in 20 to $40 \%$ of cases and can be detected as early as the 12 to 14 th week of gestation, but ultrasonography performed before the 18 to 24 th week of gestation can fail to detect significant disease [2-4]. In addition, studies performed up to the third trimester suggest that prenatal course may predict postnatal outcome [3,5-9]. The goal of prenatal management is to detect those cases of antenatal hydronephrosis that will require postnatal evaluation, timely referral to a paediatric urologist, and possible intervention [7]. The Society of Fetal Urology (SFU) developed criteria for the diagnosis and grading of antenatal hydronephrosis based upon the degree of pelvic dilatation, number of calyces seen, and the presence and severity of parenchymal atrophy [10]. In general, there is a correlation between the severity of hydronephrosis and the likelihood of having a significant renal anomaly [5,9]. In a meta-analysis of 1308 subjects with varying degrees of antenatal hydronephrosis, the risk of a pathologic postnatal outcome was estimated to be $88.3 \%, 45.1 \%$, and $11.9 \%$ for severe, moderate, and mild antenatal hydronephrosis, respectively [5].

\section{Case Report}

A 33-year-old primigravida at 34 weeks of gestation was referred to our department with fetal bilateral hydronephrosis. The US examination was performed using a Voluson E8 scanner with a 5-7 MHz convex transducer (General Electric, Boston, MA, USA). The 
male fetus had normal biometry for gestational age and amniotic fluid volume and showed bilateral gross hydronephrosis (anteroposterior diameter of $35 \mathrm{~mm}$ on both sides) with dilation of calyces. The urinary bladder appeared normal in terms of volume, shape, thickness, and voiding; ureters were not visible. We diagnosed a bilateral stenosis of the pyelo-ureteral junction with urinary obstruction (Figure 1).

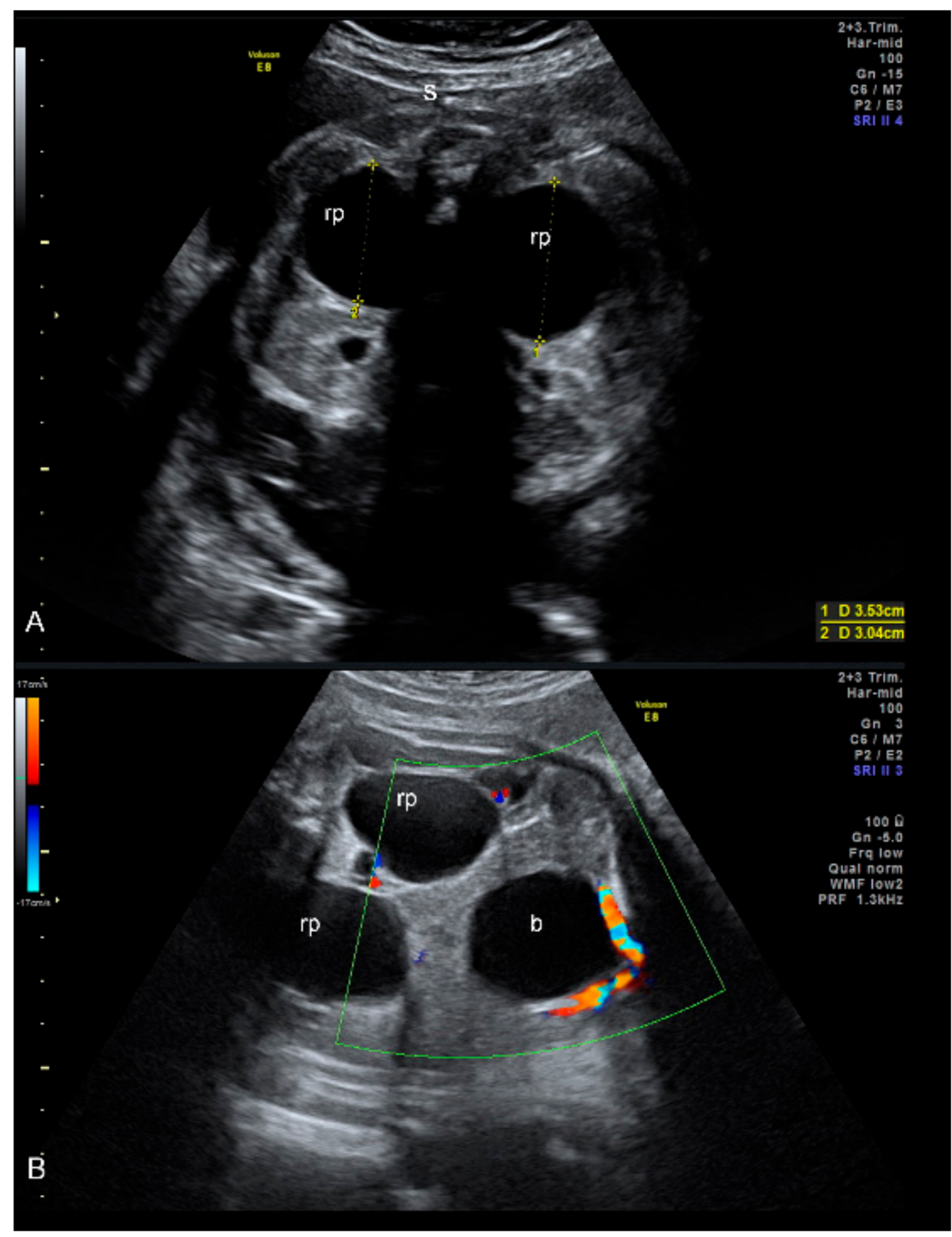

Figure 1. Prenatal ultrasound at 34 weeks of gestation (A). transverse plane of fetal abdomen; (B). coronal plane of fetal abdomen (rp: renal pelvis; b: bladder; s: spine; yellow color: anteroposterior diameter of renal pelvis; green color: color doppler box).

Subsequent US follow-up was performed every two weeks and showed stable hydronephrosis, normal bladder diameters, renal echogenicity and amniotic fluid volume, absence of any other abnormalities, and active fetal breathing movements. Indication to labour induction was given in the case of olygohydramnios. Spontaneous delivery occurred at term, and the neonate had a birthweight of $3285 \mathrm{~g}$ and was in good clinical 
condition. Antibiotic prophylaxis was administered. Follow-up ultrasound examination was carried out on the 3rd postnatal day and showed no evident anomaly: modest bilateral calico-pielic hypotony (renal pelvis A-P diameter was $5 \mathrm{~mm}$ in the right and $4 \mathrm{~mm}$ in the left kidney) and absence of ureteral dilatation or renal parenchymal alteration (Figure 2).

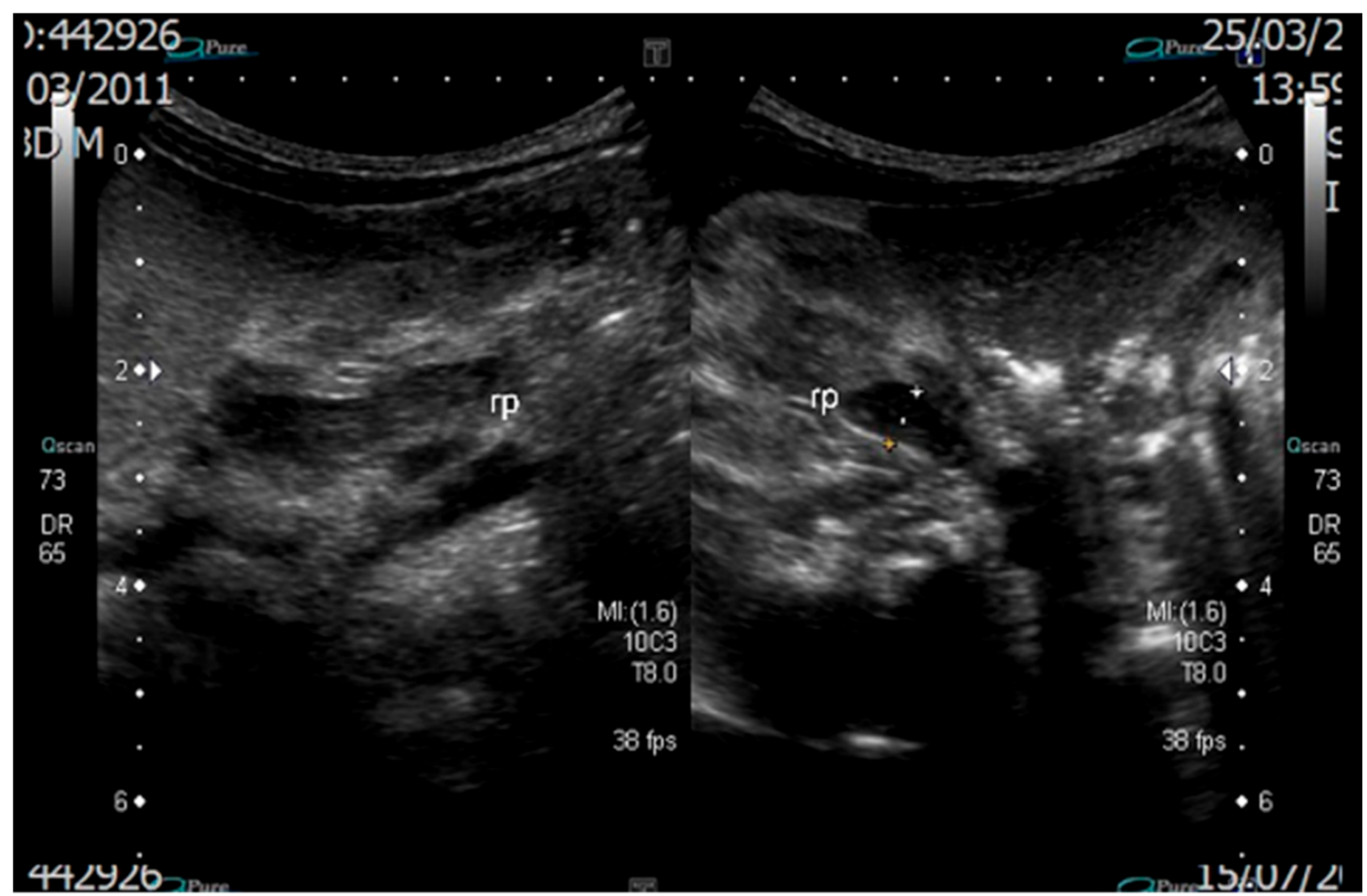

Figure 2. Follow up ultrasound examination on 3rd postnatal day (rp: renal pelvis).

The Voiding CystoUrethogram (VCU) was negative. Antibiotic prophylaxis was stopped, and the neonate was discharged with a weight of $2900 \mathrm{~g}$. The weight loss at discharge was $12 \%$ of the birth weight. At one month of age, the follow-up ultrasound examination showed moderate bilateral hydronephrosis (pelvis anteroposterior diameter: $13 \mathrm{~mm}$ dilatation bilaterally) and absence of ureteral dilatation; no additional pathologic findings were reported, in particular, the patient's growth was in normal range with an adequate weight gain. The renal parenchyma and the bladder appeared normal, and the baby was in good clinical condition. A subsequent ultrasound examination performed at 3 months of age showed that the left kidney was increased in dimension when compared to the right one ( $47 \mathrm{~mL}$ and $26 \mathrm{~mL}$, respectively) with a concomitant reduction of the parenchymal thickness $(4.2 \mathrm{~mm}$ and $7.8 \mathrm{~mm}$, respectively). This was due to the increased dilation of the calyces and renal pelvises (A-P diameter was $19 \mathrm{~mm}$, with an extra-renal development on the left side and $18 \mathrm{~mm}$ on the right side) without concomitant ureteral dilation. This finding was unchanged after micturition. The final diagnosis consisted of III degree (on the left side) and II degree pyelectasis (on the right side). The clinical picture worsened at four months of age when an ultrasound follow-up showed a severe (III degree) bilateral pyelectasis (Figure 3).

A magnetic resonance urography (MRU) confirmed the clinical picture. A diagnosis of left pyeloureteral junction syndrome and right ureteropelvic junction obstruction (UPJO) was made. A diuretic renography performed at 6 months of age showed a Mag3 renal 
scan split function of 53\% in the left kidney and $47 \%$ in the right kidney with a normal creatininemia. The nephrographic curve showed an obstructive pattern with an absent response to the Furosemide test in the left kidney. The baby underwent a successful left Anderson-Hynes pyeloplasty at 6 months of age. The child was doing well postoperatively, and the stent was removed 15 days after surgery. The patient had an uncomplicated postoperative course, and histological examination of the resected structure revealed subepithelial fibrosis. A month later, an enlargement of the left kidney was observed: the A-P diameter of the pelvis was $41 \mathrm{~mm}$, and the parenchima thickness was $5 \mathrm{~mm}$. The right kidney was $78 \times 31 \times 30 \mathrm{~mm}$ in size, with the pelvis A-P diameter of $11-12 \mathrm{~mm}$. A stent was replaced to the left kidney.

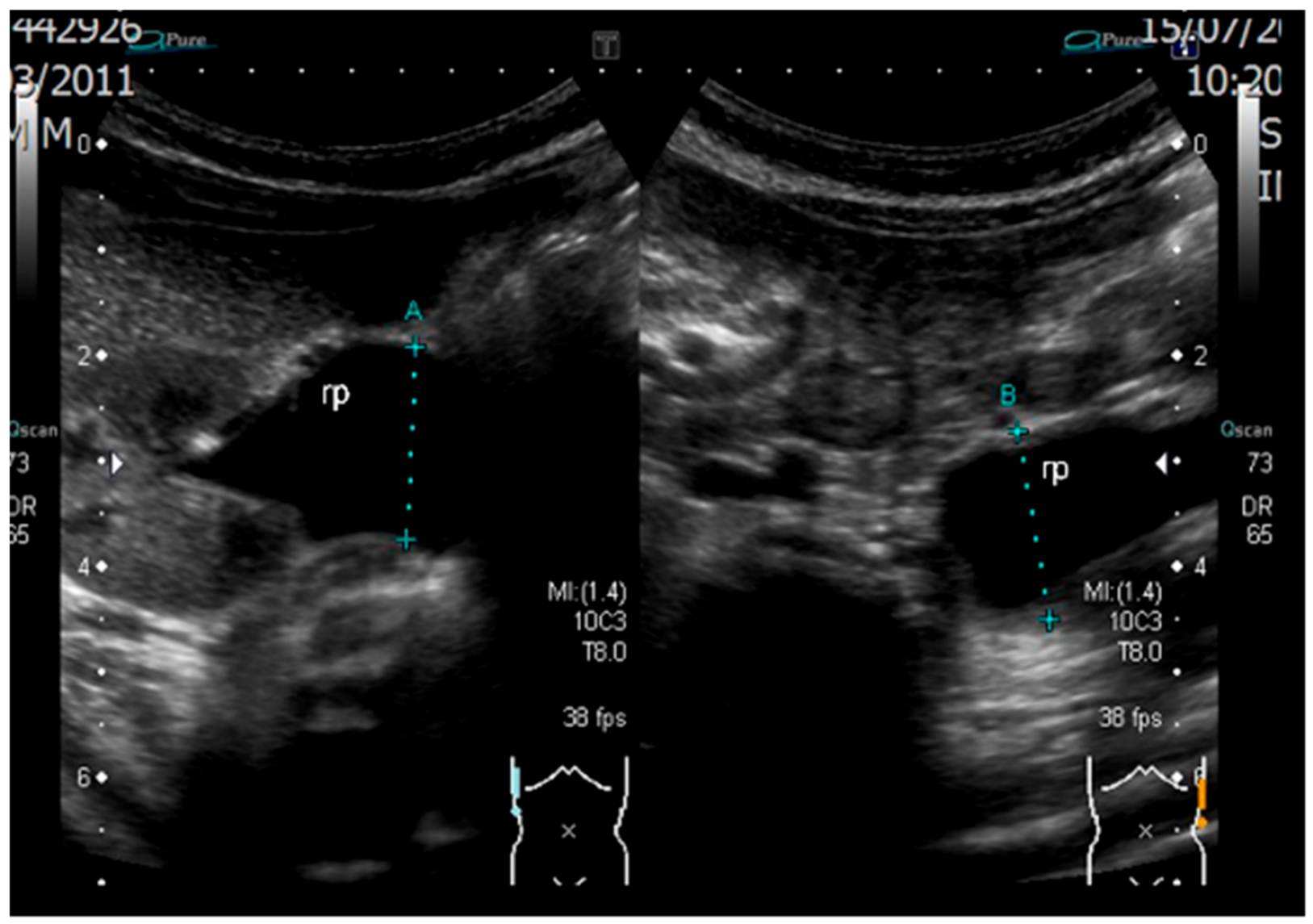

Figure 3. Follow up ultrasound at 4 months of age (rp: renal pelvis; (A): anteroposterior diameter of left renal pelvis, (B): anteroposterior diameter of right renal pelvis).

\section{Review of the Literature}

The MEDLINE and EMBASE databases were searched using a combination of the following keywords: fetal OR prenatal AND hydronephrosis OR pyeloureteral junction stenosis OR ureteropelvic junction stenosis OR vesico-ureteral reflux AND outcome OR resolution OR persistence; search was limited to articles in English available up to September 2021.

Eight articles dealt with the postnatal outcome and resolution of an antenatally detected hydronephrosis [11-18].

Six authors did not find any case of false postnatal resolution (i.e., an apparent normal US postanal followed by a new diagnosis of hydronephrosis) [11-16]. Loardi and coworkers included in their analysis 90 patients with moderate to severe prenatal hydronephrosis; the authors found a 58\% rate of postnatal resolution at the first ultrasound evaluation and risk of surgery of $25 \%$ and $60 \%$ in moderate and severe cases, respectively [11]. In a cohort of 115 fetuses with antenatal hydronephrosis, Nef et al. described 38 cases of resolution in the 
postnatal life (six cases in the first week after birth and another 32 cases of resolution in the follow-up period) [12]. An $87.2 \%$ resolution rate was noted by Zhang and coworkers with no cases of new diagnosis of hydronephrosis; lower SFU grades were associated with a more frequent resolution [13]. In 276 neonates, Elmaci and coworkers registered a resolution in $92.7 \%$ and $51.1 \%$ of cases in mild and severe grades in a mean time of 5 and 11 months, respectively [14]. In a 3-month follow-up, Shukla et al. did not record any case of false resolution; there was a $38 \%$ rate of normalization [15]. When considering a cohort of 831 neonates, Jung et al. registered a resolution in $54.3 \%$ of cases in a $26-$ month follow-up [16].

Only one article described cases of false resolution at the postnatal ultrasound, performed in the first week of life, followed by a new diagnosis of hydronephrosis at the evaluation at 1 month after birth [17]. In particular, authors described, in a cohort of 200 neonates with antenatal hydronephrosis, 99 cases of positive ultrasound at 1 month of life with a first postnatal negative evaluation (99 cases on 130 normal). However, they did not specify the exact postnatal day of the first ultrasound; it is known that there is an increased risk of underestimating the severity of hydronephrosis during the first two days after birth [4].

Interestingly, Scarborough and coworkers found that prenatal hydronephrosis resolved before birth had a recurrence in the postnatal life in $44 \%$ of cases $(32 / 72$ cases), although none of those children required surgery. Authors hypothesize that the cause of this recurrent hydronephrosis lies in the physiological changes that occur in the neonatal kidney (i.e., the great increase in glomerular filtration rate resulting in a large amount of diluted urine) [18]. A postnatal evaluation seems, therefore, to be essential, even though there is an antenatal resolution of the hydronephrosis.

\section{Discussion}

This is the first case report providing extensive iconographic evidence of postnatal resolution and recurrence with timely ultrasound imaging.

Generally, postnatal resolution of a prenatally detected hydronephrosis may occur more easily in mild cases due to a moderate degree of urinary VUR. On the other hand, the same event is less common when hydronephrosis is due to an anatomical defect such as UPJO.

We suppose that this clinical picture may be due to the reduction of the urinary output secondary to the postnatal weight loss $(12 \%)$. This percentage is more than the average, as the expected physiologic loss is 5 to $7 \%$ of birth weight for term newborns. Weight loss usually resolves by five days after birth. Newborns typically recover their birth weight by one to two weeks of age. Weight loss beyond the normal amount is an indication of poor fluid and nutrient intake and is related to hypovolemia and dehydration [19].

Hypernatremic dehydration can result in life-threatening complications, such as acute renal failure, vascular thrombosis, shock, and seizures in rare cases of extreme weight loss greater than $12 \%$ of birth weight [20-22].

The $12 \%$ weight loss on the third day after birth in our case report is an indirect sign of the neonatal dehydration state. This event may have determined a reduction of the urinary output with subsequent negativization of the hydronephrosis at the first neonatal ultrasound, which was performed on the third day after birth. We know that maternal hydration may modify the clinical picture of fetal hydronephrosis in utero: Robinson et al. and Babcook et al. in 1998 demonstrated that the fetal renal pelvis anteroposterior diameter increases with maternal hydration in both normal fetuses and those with pyelectasis $[23,24]$.

We hypothesize that fetal and neonatal hydration may influence neonatal renal pelvic diameters, as well. This hypothesis is supported by Laing et al., who reported three cases of ureteropelvic junction obstruction in infants whose initial ultrasound scan was normal at less than $24 \mathrm{~h}$ of age. They proposed dehydration and low glomerular 
filtration rates as likely causes of false-negative results [25]. Due to this risk, some authors proposed to perform a postnatal ultrasound at 1 to 2 weeks of age rather than during the first few days of life, unless significant obstruction or potential loss to follow-up is suspected [26].

In our case, the progression of the described condition was not predictable on the basis of the postnatal ultrasound alone and emphasized the importance of prenatal diagnosis, which indicates subsequent long-term follow-up. Only a few previous reports described long-term follow-up of prenatal hydronephrosis after spontaneous postnatal improvement. Previous reports indicate close follow-up during the first two years of life in order to prevent significant loss of renal function $[27,28]$. During this period, the size of renal pelvises should be stable as it has not been shown to be influenced by age in children [29].

A previous long-term follow-up study demonstrated that most children with prenatally diagnosed hydronephrosis due to UPJO required pyeloplasty during the first four years of life [30].

In our patient, prenatal ultrasound diagnosis was more reliable than postnatal imaging, emphasizing the importance of a strict postnatal urologic follow-up on prenatal indication alone, as already described in other urologic conditions [31]. Additionally, the widespread concept of neonatal assessment as the gold standard to define adequacy of prenatal diagnosis can be questioned in such situations. When approaching an early evaluation of a prenatally detected condition in a newborn, it is important to take into account all transient conditions (dehydration and weight loss in this patient) that can hide the underlying problem. Thus, for the diagnosis in question, a further urologic evaluation should be scheduled in case of discordant findings between the prenatal and postnatal periods.

\section{Conclusions}

Further research is necessary to clarify the extent and timing of postnatal investigations required in patients with a prenatal diagnosis of hydronephrosis. At present, we suggest performing serial neonatal ultrasound scans and expert urologic assessment when the postnatal resolution of severe fetal hydronephrosis is diagnosed. This policy, in our opinion, may lead to a reduction in the associated risks of sepsis for these infants.

Author Contributions: Conceptualization, P.I.C. and A.S.; methodology P.I.C.; resources, A.L. and A.S.; data curation, G.G. and M.P.; writing-original draft preparation, G.G., A.S. and M.P.; writing-review and editing, P.I.C., M.C. and A.L.; visualization A.L. and P.L.P.; supervision, M.C. and P.L.P. All authors have read and agreed to the published version of the manuscript.

Funding: This research received no external funding.

Institutional Review Board Statement: The study was conducted according to the guidelines of the Declaration of Helsinki; ethical review and approval were waived for this study due to the retrospective observational nature of our research. Data to be used for research purposes were collected and stored within an anonymized database.

Informed Consent Statement: Informed consent was obtained from the patients involved in the study. Written informed consent has been obtained from the patient to publish this paper.

Data Availability Statement: The data presented in this study are available on request from the corresponding author. The data are not publicly available due to privacy issues.

Conflicts of Interest: The authors declare no conflict of interest.

\section{References}

1. Nguyen, H.T.; Benson, C.B.; Bromley, B.; Campbell, J.B.; Chow, J.; Coleman, B.; Cooper, C.; Crino, J.; Darge, K.; Herndon, C.D.A.; et al. Multidisciplinary Consensus on the Classification of Prenatal and Postnatal Urinary Tract Dilation (UTD Classification System). J. Pediatr. Urol. 2014, 10, 982-998. [CrossRef] 
2. Robyr, R.; Benachi, A.; Daikha-Dahmane, F.; Martinovich, J.; Dumez, Y.; Ville, Y. Correlation between Ultrasound and Anatomical Findings in Fetuses with Lower Urinary Tract Obstruction in the First Half of Pregnancy. Ultrasound Obstet. Gynecol. 2005, 25, 478-482. [CrossRef] [PubMed]

3. Bromley, B.; Lieberman, E.; Shipp, T.D.; Benacerraf, B.R. The Genetic Sonogram: A Method of Risk Assessment for Down Syndrome in the Second Trimester. J. Ultrasound Med. 2002, 21, 1087-1096. [CrossRef] [PubMed]

4. Chiodini, B.; Ghassemi, M.; Khelif, K.; Ismaili, K. Clinical Outcome of Children With Antenatally Diagnosed Hydronephrosis. Front. Pediatr. 2019, 7, 103. [CrossRef] [PubMed]

5. Lee, R.S.; Cendron, M.; Kinnamon, D.D.; Nguyen, H.T. Antenatal Hydronephrosis as a Predictor of Postnatal Outcome: A Meta-Analysis. Pediatrics 2006, 118, 586-593. [CrossRef]

6. Benacerraf, B.R.; Peters, C.A.; Mandell, J. The Prenatal Evolution of a Nonfunctioning Kidney in the Setting of Obstructive Hydronephrosis. J. Clin. Ultrasound 1991, 19, 446-450. [CrossRef]

7. Yalçınkaya, F.; Özçakar, Z.B. Management of Antenatal Hydronephrosis. Pediatr. Nephrol. 2020, 35, 2231-2239. [CrossRef]

8. Duncan, K.A. Antenatal Renal Pelvic Dilatation; the Long-Term Outlook. Clin. Radiol. 2007, 62, 134-139. [CrossRef]

9. Has, R.; Sarac Sivrikoz, T. Prenatal Diagnosis and Findings in Ureteropelvic Junction Type Hydronephrosis. Front. Pediatr. 2020, 8, 492. [CrossRef]

10. Fernbach, S.K.; Maizels, M.; Conway, J.J. Ultrasound Grading of Hydronephrosis: Introduction to the System Used by the Society for Fetal Urology. Pediatr. Radiol. 1993, 23, 478-480. [CrossRef]

11. Loardi, C.; Signorelli, M.; Gregorini, M.; Marella, D.; Torri, F.; Zambelloni, C.M.; Omodei, U.; Odicino, F. Moderate and Severe Fetal Pyelectasis: Correlation between Prenatal Aspects and Postnatal Outcome. J. Neonatal Perinatal Med. 2020, 13, 91-96. [CrossRef]

12. Nef, S.; Neuhaus, T.J.; Spartà, G.; Weitz, M.; Buder, K.; Wisser, J.; Gobet, R.; Willi, U.; Laube, G.F. Outcome after Prenatal Diagnosis of Congenital Anomalies of the Kidney and Urinary Tract. Eur. J. Pediatr. 2016, 175, 667-676. [CrossRef]

13. Zhang, D.; Sun, X.; Chen, X.; Yu, B.; Li, T.; Cheng, Y.; Ye, M.; Lin, L.; Ma, L.; Zhao, Y.; et al. Ultrasound Evaluation for Prediction of Outcomes and Surgical Decision in Fetal Hydronephrosis. Exp. Ther. Med. 2019, 18, 1399-1406. [CrossRef]

14. Elmaci, A.M.; Dönmez, M.I. Time to Resolution of Isolated Antenatal Hydronephrosis with Anteroposterior Diameter $\leq 20 \mathrm{Mm}$. Eur. J. Pediatr. 2019, 178, 823-828. [CrossRef] [PubMed]

15. Shukla, P.; Kumar, M.; Puri, A.; Siva, P.M. Correlation of Antenatal Ultrasound Parameters with the Postnatal Outcome of Bilateral Fetal Hydronephrosis. J. Obstet. Gynaecol. India 2020, 70, 202-207. [CrossRef] [PubMed]

16. Jung, J.; Lee, J.H.; Kim, K.S.; Park, Y.S. Utility of Society for Fetal Urology and Anteroposterior Pelvic Diameter Grading Systems for Estimating Time to Resolution of Isolated Hydronephrosis: A Single Center Study. J. Urol. 2020, 204, 1048-1053. [CrossRef] [PubMed]

17. Sadeghi-Bojd, S.; Kajbafzadeh, A.-M.; Ansari-Moghadam, A.; Rashidi, S. Postnatal Evaluation and Outcome of Prenatal Hydronephrosis. Iran J. Pediatr. 2016, 26, e3667. [CrossRef] [PubMed]

18. Scarborough, P.L.; Ferrara, E.; Storm, D.W. Should Prenatal Hydronephrosis That Resolves before Birth Be Followed Postnatally? Analysis and Comparison to Persistent Prenatal Hydronephrosis. Pediatr. Nephrol. 2015, 30, 1485-1491. [CrossRef] [PubMed]

19. Gartner, L.M.; Morton, J.; Lawrence, R.A.; Naylor, A.J.; O’Hare, D.; Schanler, R.J.; Eidelman, A.I. American Academy of Pediatrics Section on Breastfeeding Breastfeeding and the Use of Human Milk. Pediatrics 2005, 115, 496-506. [CrossRef]

20. Pelleboer, R.A.; Bontemps, S.T.H.; Verkerk, P.H.; Van Dommelen, P.; Pereira, R.R.; Van Wouwe, J.P. A Nationwide Study on Hospital Admissions Due to Dehydration in Exclusively Breastfed Infants in the Netherlands: Its Incidence, Clinical Characteristics, Treatment and Outcome. Acta Paediatr. 2009, 98, 807-811. [CrossRef] [PubMed]

21. Shroff, R.; Hignett, R.; Pierce, C.; Marks, S.; van't Hoff, W. Life-Threatening Hypernatraemic Dehydration in Breastfed Babies. Arch. Dis. Child. 2006, 91, 1025-1026. [CrossRef]

22. Sarin, A.; Thill, A.; Yaklin, C.W. Neonatal Hypernatremic Dehydration. Pediatr. Ann. 2019, 48, e197-e200. [CrossRef]

23. Robinson, J.N.; Tice, K.; Kolm, P.; Abuhamad, A.Z. Effect of Maternal Hydration on Fetal Renal Pyelectasis. Obstet. Gynecol. 1998, 92, 137-141. [CrossRef]

24. Babcook, C.J.; Silvera, M.; Drake, C.; Levine, D. Effect of Maternal Hydration on Mild Fetal Pyelectasis. J. Ultrasound Med. 1998, 17, 539-544. [CrossRef]

25. Laing, F.C.; Burke, V.D.; Wing, V.W.; Jeffrey, R.B.; Hashimoto, B. Postpartum Evaluation of Fetal Hydronephrosis: Optimal Timing for Follow-up Sonography. Radiology 1984, 152, 423-424. [CrossRef]

26. Wiener, J.S.; O'Hara, S.M. Optimal Timing of Initial Postnatal Ultrasonography in Newborns with Prenatal Hydronephrosis. J. Urol. 2002, 168, 1826-1829. [CrossRef]

27. Gatti, J.M.; Broecker, B.H.; Scherz, H.C.; Perez-Brayfield, M.R.; Kirsch, A.J. Antenatal Hydronephrosis with Postnatal Resolution: How Long Are Postnatal Studies Warranted? Urology 2001, 57, 1178. [CrossRef]

28. Onen, A.; Jayanthi, V.R.; Koff, S.A. Long-Term Followup of Prenatally Detected Severe Bilateral Newborn Hydronephrosis Initially Managed Nonoperatively. J. Urol. 2002, 168, 1118-1120. [CrossRef]

29. Tsai, T.C.; Lee, H.C.; Huang, F.Y. The Size of the Renal Pelvis on Ultrasonography in Children. J. Clin. Ultrasound 1989, $17,647-651$. [CrossRef] 
30. Chertin, B.; Pollack, A.; Koulikov, D.; Rabinowitz, R.; Hain, D.; Hadas-Halpren, I.; Farkas, A. Conservative Treatment of Ureteropelvic Junction Obstruction in Children with Antenatal Diagnosis of Hydronephrosis: Lessons Learned after 16 Years of Follow-Up. Eur. Urol. 2006, 49, 734-738. [CrossRef]

31. Cavoretto, P.; Lesma, A.; Spagnolo, D.; Valsecchi, L.; Negretto, A.; Candiani, M. Prenatal Sonographic Monitoring of Idiopathic Megacystis. J. Clin. Ultrasound 2013, 41, 116-118. [CrossRef] [PubMed] 